\title{
Australian Journal of Crop Science \\ Genetic variability of cultivated plum (Prunus domestica L. \& Prunus salicina Lindl.) in Morocco assessed by ISSR markers
}

\author{
Youssef Ait bella, Said Bouda, Youssef Khachtib, Abdelmajid Haddioui* \\ Laboratory of Biotechnology and Valorisation of Plant Genetic Resources, Faculty of Sciences and \\ Techniques, University of Sultan Moulay Slimane, BeniMellal, Morocco
}

\section{Corresponding author: a.haddioui@usms.ma}

\begin{abstract}
Moroccan plum cultivars were genetically characterized for assessing diversity and relatedness. In this study, a total of 23 plum cultivars were analyzed using 14 Inter-Simple Sequence Repeat (ISSR) primers. A total of 100 bands were obtained, of which 84 were polymorphic (84\%). The mean values of PIC, Rp, I and Ht were $0.45 ; 3.03 ; 0.42$ and 0.27 , respectively, implying the important genetic variability between the plum cultivars. Furthermore, the coefficient of genetic differentiation ( $\mathrm{G}_{\mathrm{ST}}$ ) between all groups was 0.21 indicating that $21 \%$ of total genetic variability was between groups and $79 \%$ was within groups. The UPGMA dendrogram and Bayesian model-based clustering approach identified four gene pools of cultivars independently of their geographic origin and denomination. These results showed that the ISSRs markers can be a useful tool for detecting molecular polymorphism and to survey the genetic diversity in this fruit crop.
\end{abstract}

Keywords: Plum, Morocco, ISSR markers, genetic diversity, clustering analysis.

Abbreviations: ISSR_Inter Simple Sequence Repeats; Hs_The diversity within group; Ht_ The total gene diversity; GST_ The coefficient of gene differentiation.

\section{Introduction}

Plums belong to the genus Prunus are naturally distributed in the temperate regions of the Northern Hemisphere. They are cultivated over a wide range of climatic conditions. They are native to Europe and Asia (Fábregas, 1995). The most economically important plum species are generally classified into two groups: the European type (Prunus domestica L.) probably originated in Eastern Europe or western Asia around the Caucasus and the Caspian Sea (Hummer and Janick, 2009; Das et al., 2011) and the Japanese type (Prunus salicina Lindl.) originated from China and domesticated in Japan (Ramming and Cociu, 1991). There are also several native plum species occur in some countries, such as North America ( $P$. americana, $P$. hortulana, $P$. subcordata) and the UK ( $P$. spinosa, $P$. institia). About 12.6 million tons of plum was produced in the world in 2018 (FAOSTAT, 2018).

Plums are among the most important stone fruit crop (Bhutani and Joshi, 1995). Fruits are consumed both in fresh and processed form, which are an excellent source of nutriments and contributes extensively to human nutrition (Cao et al., 1997). It's also an important source of components influencing human health (StacewiczSapuntzakis et al., 2001). It contains organic acids, carbohydrates, fibers, aromatic substances, tannins and enzymes.

P. domestica and P.salicina are the most important plum species cultivated in Morocco in different climatic regions on an area of about 15451 hectares with a total production of 205222 tons (FAOSTAT, 2018). The production is based mainly on early Japanese varieties such as Golden japan, Santa Rosa and Methley that are known as table varieties and Stanley variety of drying (Walali and Skiredj, 2003). There are also other varieties of late Japanese plum table, derived from Californian research program (USA) as Black Amber and Angeleno (Oukabli and Mamouni, 2005; Laabassi and Laroussi, 2010). In addition, there are many plum cultivars belonging to $P$. domestica including very old ones with unknown origin and non-breeding programs (Mahhou and Raquib, 2006). Traditionally, the genetic diversity of plums has been studied using pomological traits (Nisar et al., 2015; Kumar et al., 2018; Manco et al., 2019). However, morphological traits are limited because of their environmental fluctuations. In recent years, many molecular markers have been used to study the genetic diversity and cultivar identification of plum, such as Restriction Fragment Length Polymorphism (Bouhadida et al., 2007; Ben Mustapha et al., 2015), Random Amplified Polymorphic DNA (Ben Tamarzizt et al., 2009), Amplified Fragment Length Polymorphism (Aradhya et al., 2004), Simple Sequence Repeat (Horvath et al., 2011; Manco et al., 2019; Baraket et al., 2019) and Inter-Simple Sequence Repeat (Liu et al., 2007; Athanasiadis et al., 2013; Wu et al., 2018). It is worth noting that although many research reports are available for this plant in several parts of the world; little data is available on its variability and adaptability in Morocco. Our first study on morphological characters showed high phenotypic diversity in 30 cultivars collected in different regions in Morocco (Ait 
Bella et al., 2018). The purpose of this investigation was to study the level and organisation of the genetic diversity and relatedness among 23 cultivars using ISSR markers.

\section{Results}

\section{ISSR polymorphism}

PCRs using 14 ISSR amplified 100 bands of 23 cultivars, of which $83.14 \%$ were polymorphic (Table 1 ). Number of amplified fragments ranged from 4 (UBC818 and UBC889) to 12 (UBC810), with an average of 7.14. UBC810, UBC818 and UBC 844 were the most polymorphic primers $(100 \%)$, while UBC825, UBC845, UBC848 and UBC857 were only scored in $71.42 \%$ of the polymorphic bands. The PIC values for the 14 primers showed mean value of 0.45 with the lowest value of 0.34 is shown by UBC848 and the highest value 0.49 shown by (UBC810, UBC825 and UBC868). For the resolving power, $(\mathrm{Rp})$ used to determine the ability of primers to differentiate plum, the values ranged from 1.13 (UBC889) to 6.86 (UBC810) with an average of 3.03. Regarding the effective multiplex ratio (EMR) and the marker index (MI), UBC810 primer produced the highest mean value of EMR (12) and MI (5.88) and lowest mean value is shown by UBC889 (EMR = $2.25)$ and $(\mathrm{MI}=1.05)$.

\section{Genetic diversity}

Genetic variability analysis of 23 cultivars studied is shown in Table 2. The results showed that the number of observed alleles ( $\mathrm{Na}$ ) ranged from 1.71 (UBC825, UBC845, UBC848 and UBC857) to 2 (UBC810, UBC818 and UBC844) with an average of 1.84. The highest effective number of alleles ( $\mathrm{Ne}$ ) was found for primer UBC818 (1.77) while the lowest value was recorded for primer UBC855 (1.17), with a mean of 1.49. Based on the Shannon diversity index (I) values, UBC889 showed the minimum value of 0.21 and UBC818 the maximum value 0.62 , with an average of 0.42 . The total gene diversity $(\mathrm{Ht})$ ranged from 0.12 for UBC855 to 0.39 for UBC818 with an average value of 0.27 . The gene diversity within geographic group (Hs) varied from 0.11 to 0.30 with an average of 0.21 , while the highest and lowest values were obtained for the primer UBC818 and UBC855, respectively. Nei's coefficient of genetic differentiation $\left(\mathrm{G}_{\mathrm{ST}}\right)$ was 0.21 , indicating that only $21 \%$ of total genetic variability was distributed among the groups and $79 \%$ was within groups. The gene flow $(\mathrm{Nm})$ varied between 0.84 for the primer UBC848 and 14.78 for the primer UBC827 with an average of 1.83. On the other hand, the matrix of genetic differentiation between cultivars groups was not associated with their corresponding geographic distance $(r=0.12$, $\mathrm{p}=0.36$ ) after Mantel test execution.

\section{Clustering analyses}

The UPGMA dendrogram was constructed based on Dice's coefficient. It showed that plum cultivars were grouped in two major groups designated as I and II (Fig. 1). The first group revealed two sub-clusters, namely (Ia) and (Ib). The first sub-group (la) comprised of cultivars Santa Rosa, Safra 4, Lmozari, Golden Japan and Frigo, and the second subgroup (Ib) contained cultivars Black Amber, Royal Diamon, Angeleno, Safra 3, Lbyad 1, Lbyad 2, Lbayda and Safra 1. The second main group (II) is also bifurcated in two sub-clusters (IIa) and (IIb). The first sub-cluster (Ila) grouped cultivars Fortune, Lbide, Safrarkika, Hamra1, Hamra2, Hamra3, Dlahi and tabarkakacht. It's worthy to mention that some cultivars (Hamra1, Hamra2, Hamra3, Dlahi and Tabarkakacht), which gathered in this last sub-group, had the same skin color (red) that is used by farmers to give them these denominations. The second sub-cluster (IIb) included only two cultivars Stanley and Safra2.

These results showed that some cultivars under different names are grouped together (HAM1, DLH and TAB) and (BLA2 and ROD), suggest that they could be synonyms. Indeed, the plum cultivar are denominated by farmer based on their fruit characteristic (skin color, size, origin, flavor) leading often to the problem of mislabeling. In contrast, others cultivars with same names were grouped differently like Safra1, Safra2, Safra3 and Safra4, which could be homonyms. On the other hand, these groups were not correlated with the geographic distances between cultivars $(r=0.046, p=0.301)$ after Mantel test execution.

The genetic structure of plum cultivars was analyzed with a model-based Bayesian cluster approach (Structure software). The ad-hoc quantity based on the second order rate of change of the likelihood function $(\Delta K)$ (Evanno et al., 2005) showed that the accurate representation of Moroccan plum genetic structure was observed for $\mathrm{K}=4(\Delta \mathrm{K}=6.85)$ (Fig. 2). Based on the permuted average $Q$-matrix generated by Clumpp for the 10 Structure runs, the highest $\mathrm{H}^{\prime}$ was also observed for $\mathrm{K}=4\left(\mathrm{H}^{\prime}=0.922\right)$. This model was considered the best to depict the genetic structure of plum in Morocco. Individuals with a membership coefficient less than 0.8 were considered as admixed; 20 individuals among the 23 studied $(86.95 \%)$ were assigned to one of the model's defined groups. According to the model at $K=4$, plum cultivars were assigned to four genetically different clusters. The first one (red) is composed of cultivars Royal Diamond, Black Amber and Angeleno with a membership coefficient between 0.88 and 0.97 . The second cluster (green) contains cultivars Hamra1, Dlahi, Tabarkakacht, Hamra2 and Hamra3, all having a membership coefficients greater than 0.90 , except cultivars Hamra1 and Dlahi that could be considered as admixed (coefficients 0.79 and 0.53 , respectively). The third cluster (blue) included cultivars Lbyade1, Safra1, Lbyade2 and Lbayda with a membership coefficient greater than 0.94. The last cluster consisted of Fortune, Safra2, Safrarkika, Lbide, Stanley, Golden-japan, Lmozari, Santa-rosa, Frigo and Safra 4 with more than $85 \%$ of the assignation probability, the cultivar Safra3 with an assigned probability of $56 \%$, could be considered as admixed. As for cluster analysis, the cultivars Hamra1, Tabarkakacht and Dlahi (with different appellations and red skin color) were grouped together in the blue cluster. Under the same denominations, cultivars Safra1, Safra2, Safra3 and Safra4 were assembled differently in two clusters (blue and yellow). Accordingly, the genetic structure of investigated plum cultivars within four main gene pools was done independently of their denominations and geographical origins.

\section{Discussion}

By revealing sufficient markers to characterize Moroccan plum cultivars, the ISSR markers have proved to be efficient; in one hand, to resolve mislabeling in plum and on other hand to investigate its genetic variability. The percentage of polymorphic bands obtained in the present study (83.14\%) was comparable to that found in previous reports by Athanasiadis et al., 2013; Ali et al., (2015) in Greek plum cultivars based on ISSR markers (81.81\%) and Iraq plum cultivars using AFLP markers (81.1\%), respectively. 
Table 1. Characteristics of the tested ISSR primers and statistical parameters: polymorphism information content, resolving powers, effective multiplex ratio and marker index.

\begin{tabular}{|c|c|c|c|c|c|c|c|c|}
\hline Primer & Sequence $5^{\prime}-3^{\prime}$ & $\begin{array}{l}\text { total } \\
\text { band }\end{array}$ & $\begin{array}{l}\text { Polymorphic } \\
\text { bands }\end{array}$ & $\begin{array}{l}\text { Percentage of } \\
\text { Polymorphic bands }\end{array}$ & $\mathrm{PIC}$ & $\mathrm{Rp}$ & EMR & MI \\
\hline UBC 810 & $(\mathrm{GA}) 8 \mathrm{~T}$ & 12 & 12 & 100 & 0.49 & 6.86 & 12 & 5.88 \\
\hline UBC 818 & (CA)8G & 4 & 4 & 100 & 0.39 & 1.91 & 4 & 1.56 \\
\hline UBC 825 & $(\mathrm{AC}) 8 \mathrm{~T}$ & 7 & 5 & 71.42 & 0.49 & 3.04 & 3.57 & 1.75 \\
\hline UBC 827 & $(\mathrm{AC}) 8 \mathrm{G}$ & 5 & 4 & 80 & 0.47 & 2.69 & 3.2 & 1.50 \\
\hline UBC 841 & (GA)8YC & 8 & 7 & 87.5 & 0.45 & 2.60 & 6.12 & 2.75 \\
\hline UBC 844 & (CT)8RC & 7 & 7 & 100 & 0.48 & 3.21 & 7 & 3.36 \\
\hline UBC 845 & (CT)8RG & 7 & 5 & 71.42 & 0.47 & 3.21 & 3.57 & 1.67 \\
\hline UBC 848 & (CA)8RG & 7 & 5 & 71.42 & 0.34 & 3.13 & 3.57 & 1.21 \\
\hline UBC 853 & (TC)8RT & 6 & 5 & 83.33 & 0.41 & 2.43 & 4.16 & 1.70 \\
\hline UBC 855 & $(\mathrm{AC}) 8 \mathrm{YT}$ & 8 & 6 & 75 & 0.47 & 2.26 & 4.5 & 2.11 \\
\hline UBC 857 & $(\mathrm{AC}) 8 \mathrm{YG}$ & 7 & 5 & 71.42 & 0.40 & 2.25 & 3.57 & 1.43 \\
\hline UBC 861 & $(\mathrm{ACC}) 6$ & 8 & 7 & 87.5 & 0.45 & 3.30 & 6.12 & 2.75 \\
\hline UBC 868 & (GAA)5 & 10 & 9 & 90 & 0.49 & 4.52 & 8.1 & 3.97 \\
\hline UBC 889 & $(\mathrm{AC}) 7$ & 4 & 3 & 75 & 0.47 & 1.13 & 2.25 & 1.05 \\
\hline Average & & 7.14 & 6 & 83.14 & 0.45 & 3.03 & 5.12 & 2.33 \\
\hline
\end{tabular}

$\mathrm{Y}=(\mathrm{C}, \mathrm{T}), \mathrm{R}=(\mathrm{A}, \mathrm{G}) ; \mathrm{PIC}=$ polymorphic information content; $\mathrm{Rp}=$ resolving power; $\mathrm{EMR}=$ Effective Multiplex Ratio; $\mathrm{MI}=$ Marker Index

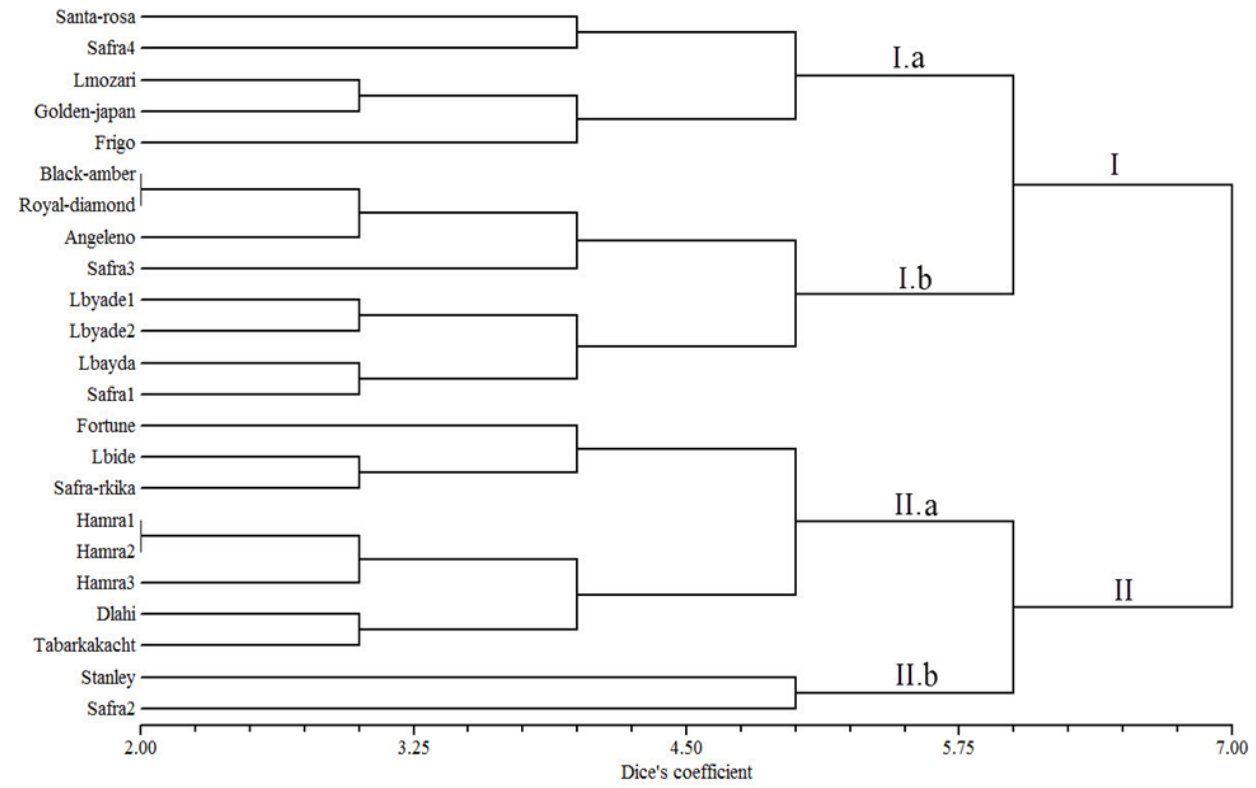

Fig 1. UPGMA dendrogram of the 23 plum cultivars based on 84 ISSR markers.

Table 2. Genetic diversity analysis of four geographic groups of plum

\begin{tabular}{|c|c|c|c|c|c|c|c|c|}
\hline Amorce & Simple size & $\mathrm{Na}$ & $\mathrm{Ne}$ & $\mathrm{Ht}$ & Hs & Gst & $\mathrm{Nm}$ & I \\
\hline UBC 810 & 23 & 2 & 1.57 & 0.30 & 0.22 & 0.24 & 1.51 & 0.50 \\
\hline UBC 818 & 23 & 2 & 1.77 & 0.39 & 0.30 & 0.22 & 1.76 & 0.62 \\
\hline UBC 825 & 23 & 1.71 & 1.42 & 0.22 & 0.14 & 0.36 & 0.88 & 0.35 \\
\hline UBC 827 & 23 & 1.8 & 1.57 & 0.30 & 0.29 & 0.03 & 14.78 & 0.46 \\
\hline UBC 841 & 23 & 1.87 & 1.32 & 0.22 & 0.16 & 0.24 & 1.54 & 0.34 \\
\hline UBC 844 & 23 & 2 & 1.56 & 0.34 & 0.25 & 0.26 & 1.41 & 0.51 \\
\hline UBC 845 & 23 & 1.71 & 1.42 & 0.26 & 0.22 & 0.15 & 2.83 & 0.38 \\
\hline UBC 848 & 23 & 1.71 & 1.61 & 0.29 & 0.18 & 0.37 & 0.84 & 0.46 \\
\hline UBC 853 & 23 & 1.83 & 1.62 & 0.31 & 0.28 & 0.11 & 3.79 & 0.50 \\
\hline UBC 855 & 23 & 1.75 & 1.17 & 0.12 & 0.11 & 0.04 & 10.49 & 0.22 \\
\hline UBC 857 & 23 & 1.71 & 1.57 & 0.30 & 0.24 & 0.20 & 1.96 & 0.42 \\
\hline UBC 861 & 23 & 1.87 & 1.58 & 0.34 & 0.29 & 0.15 & 2.67 & 0.49 \\
\hline UBC 868 & 23 & 1.9 & 1.49 & 0.27 & 0.20 & 0.27 & 1.33 & 0.44 \\
\hline UBC 889 & 23 & 1.75 & 1.18 & 0.15 & 0.14 & 0.06 & 7.43 & 0.21 \\
\hline Average & 23 & 1.84 & 1.49 & 0.27 & 0.21 & 0.21 & 1.83 & 0.42 \\
\hline
\end{tabular}
Shannon's Information index. 


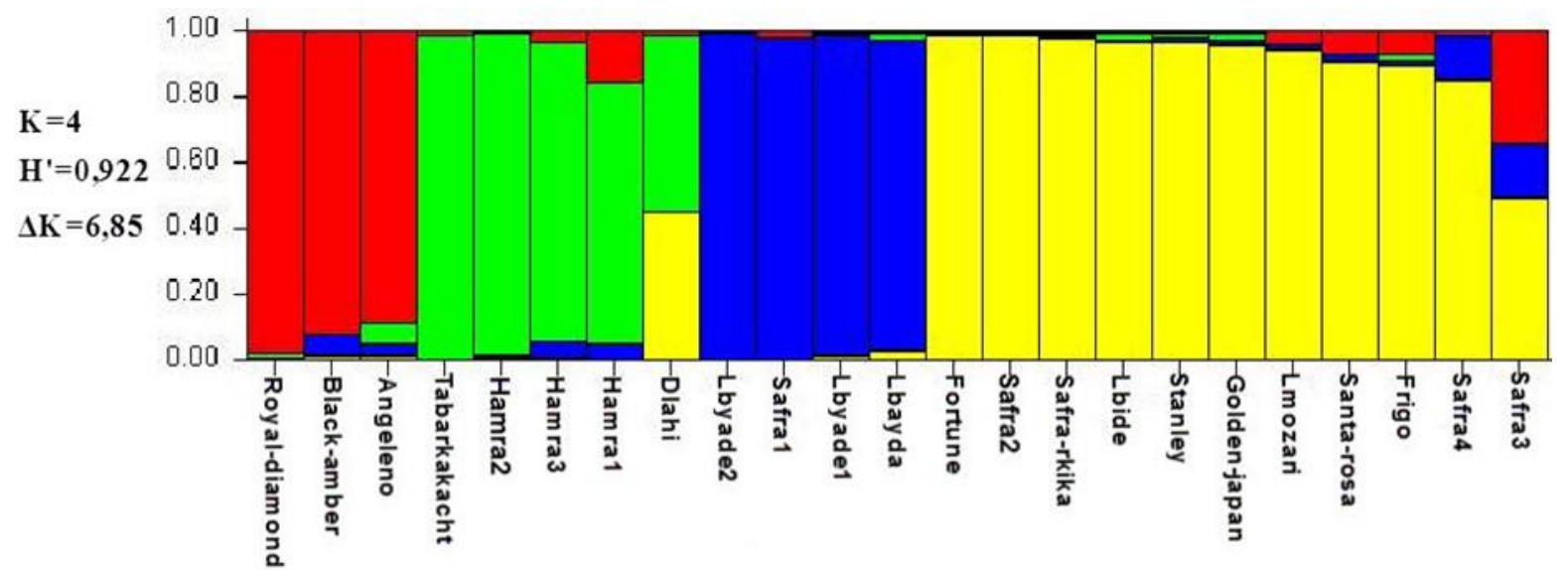

Fig 2. Genetic clustering obtained from the Structure analysis $(\mathrm{N}=23)$. Each cultivar is represented by a single vertical column, divided into K colors. The colored segment shows the individual's estimated proportion of membership to that genetic cluster.

Table 3. Appellation and geographic origin of the 23 plum cultivars.

\begin{tabular}{|c|c|c|c|c|c|c|}
\hline Group & Cultivars & Locality & Code & $\begin{array}{l}\text { Latitude } \\
\text { Noth }\end{array}$ & $\begin{array}{l}\text { Longitude } \\
\text { West }\end{array}$ & Species \\
\hline \multirow{5}{*}{$\begin{array}{l}\text { Marrakech } \\
\text { (MAR) }\end{array}$} & Santa rosa** & Asguine (40 km S of Marrakech) & SAR & $31^{\circ} 21$ & $7^{\circ} 45$ & Prunus salicina Lindl. \\
\hline & Hamra1* & Anzo1 (19 km S of El Attaouia) & HAM1 & $30^{\circ} 41$ & $7^{\circ} 16^{\prime}$ & Prunus domestica L. \\
\hline & Hamra2* & Anzo2 (17 km S of El Attaouia) & HAM2 & $31^{\circ} 41$ & $7^{\circ} 17^{\prime}$ & Prunus domestica L. \\
\hline & Lbyade2* & Asguine (40 km S of Marrakech) & LBY2 & $31^{\circ} 21$ & $7^{\circ} 45$ & Prunus domestica L. \\
\hline & Lbide* & Magaste (46 Km S of Marrakech) & LBI & $31^{\circ} 14$ & $7^{\circ} 40$ & Prunus domestica L. \\
\hline \multirow{5}{*}{$\begin{array}{l}\text { Beni Mellal } \\
\text { (BM) }\end{array}$} & Fortune** & Sidi Jaber (10 Km W of Beni Mellal) & FOR & $32^{\circ} 22$ & $6^{\circ} 26$ & Prunus salicina Lindl. \\
\hline & Stanley** & Aghbala (111 Km E of Beni Mellal) & STA & $32^{\circ} 28$ & $5^{\circ} 39$ & Prunus domestica L. \\
\hline & Tabarkakacht* & Ain Assardoun ( $2 \mathrm{~km} \mathrm{~S}$ of Beni Mellal) & $\mathrm{TAB}$ & $32^{\circ} 19$ & $6^{\circ} 19$ & Prunus domestica L. \\
\hline & Lbayda* & Ain assardoun ( $2 \mathrm{~km} \mathrm{~S}$ of Beni Mellal & LBA & $32^{\circ} 19$ & $6^{\circ} 19$ & Prunus domestica $\mathrm{L}$. \\
\hline & Safra1* & Sidi Jaber (10 Km W of Beni Mellal) & SAF1 & $32^{\circ} 22$ & $6^{\circ} 26$ & Prunus domestica L. \\
\hline \multirow[t]{11}{*}{ Meknes (MEK) } & Black amber** & Bouderbala (24 Km E of Meknes) & BLA & $33^{\circ} 49$ & $5^{\circ} 17$ & Prunus salicina Lindl. \\
\hline & Lmozari* & Ait Ouallal (40 Km E of Meknes) & LMO & $33^{\circ} 48$ & $5^{\circ} 11$ & Prunus domestica L. \\
\hline & Safra4* & Amane Syernine (30 Km S of El-Hajab) & SAF4 & $33^{\circ} 37$ & $5^{\circ} 25$ & Prunus domestica L. \\
\hline & Safra rkika* & Amane Syernine ( $30 \mathrm{Km} \mathrm{S}$ of El-Hajab) & SARK & $33^{\circ} 37$ & $5^{\circ} 25$ & Prunus domestica L. \\
\hline & Royal diamond** & Ain Chifa ( $7 \mathrm{Km} \mathrm{N}$ of Imouzzer-kandar) & ROD & $33^{\circ} 46$ & $5^{\circ} 1$ & Prunus salicina Lindl. \\
\hline & Angeleno** & Ain Chifa (7 Km N of Imouzzer-kandar) & ANG & $33^{\circ} 46$ & $5^{\circ} 1$ & Prunus salicina Lindl. \\
\hline & Golden japan** & Ain Chifa (7 Km N of Imouzzer-kandar) & GOJ & $33^{\circ} 46^{\prime}$ & $5^{\circ} 1$ & Prunus salicina Lindl. \\
\hline & Hamra3* & Ait Saleh ( $5 \mathrm{~km} \mathrm{~N}$ of Imouzzer-kandar) & HAM3 & $33^{\circ} 46^{\prime}$ & $5^{\circ} 0$ & Prunus domestica L. \\
\hline & Safra2* & Ain Chifa (7 Km N of Imouzzer-kandar) & SAF2 & $33^{\circ} 46$ & $5^{\circ} 1$ & Prunus domestica L. \\
\hline & Safra3* & Ait Saleh ( $5 \mathrm{~km} \mathrm{~N}$ of Imouzzer-kandar) & SAF3 & $33^{\circ} 46^{\prime}$ & $5^{\circ} 0$ & Prunus domestica L. \\
\hline & Frigo* & Ait Saleh ( 5 km N of Imouzzer-kandar) & FRI & $33^{\circ} 46^{\prime}$ & $5^{\circ} 0$ & Prunus domestica L. \\
\hline \multirow{2}{*}{$\begin{array}{l}\text { Taounate } \\
\text { (TAO) }\end{array}$} & Dlahi* & Bouadel (15 Km E of Taounate) & DLH & $34^{\circ} 34$ & $4^{\circ} 30$ & Prunus domestica L. \\
\hline & Lbyade1* & Bouadel (15 Km E of Taounate) & LBY1 & $34^{\circ} 34$ & $4^{\circ} 30$ & Prunus domestica L. \\
\hline
\end{tabular}

* Local cultivars. ${ }^{* *}$ Introduced cultivars.

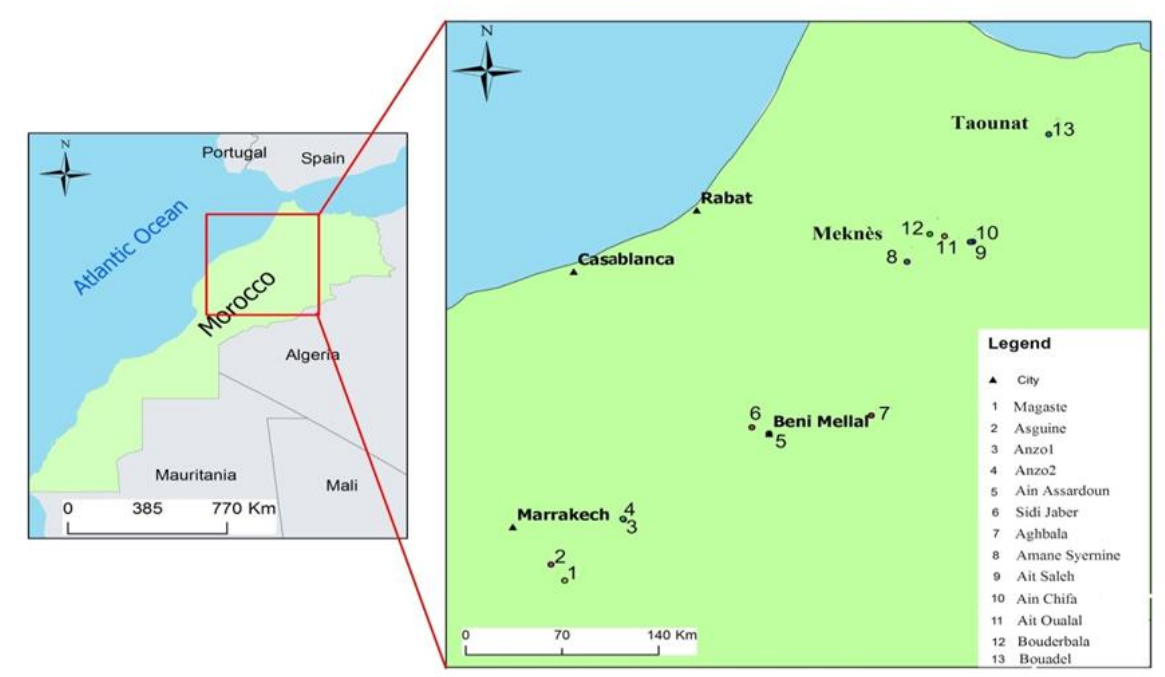

Fig 3. Map of Morocco showing the locations of the plum cultivars analyzed. 
In addition, the mean value of PIC (0.45) indicated that ISSR markers exhibited high performance in genetic identification of this species. Also, the values of resolving power Rp (3.03) indicated the efficacy of these ISSR primers to discriminate Moroccan plum. This value is higher than that obtained by Athanasiadis et al. (2013) in Greek plum germplasm using ISSRs markers (0.91) and by Ilgin et al. (2009) in Turkish plum using AFLP markers (0.91). Shannon's information index (I) showed an average value of 0.42 . This result is higher than that reported by Carrasco et al. (2012) (0.27) for Japanese plum and by Wu et al. (2018) (0.38) for Chinese plum. Indeed, the polymorphism recorded is confirmed by the value of the Shannon index (0.42).

The high multi-locus value of $\mathrm{Ht}(0.27)$ suggests the presence of a high level of polymorphism of studied cultivars. This value was higher than that found by Wu et al. (2018) $(\mathrm{Ht}=0.23)$ in Chinese plum using ISSRs markers. However, the gene diversity within the groups (Hs) was 0.21 . This value was similar to that reported by Wu et al. (2018) in Chinese plum cultivars ( $\mathrm{Hs}=0.21$ ).

The high genetic diversity obtained in plum cultivated in Morocco was in agreement with general trend for long-lived woody perennial species ( $\mathrm{Ht}=0.28$ from 195 entries) and for angiosperms species ( $\mathrm{Ht}=0,28$ from 73 entries) (Hamrick et al., 1992). Moreover, this high level of genetic diversity may be explained by the less gene flow between the different localities.

The coefficient of genetic differentiation between the groups was large $\left(\mathrm{G}_{\mathrm{ST}}=0.21\right)$. This result was higher than that obtained by $\mathrm{Wu}$ et al. (2018) in Chinese plum $\left(\mathrm{G}_{\mathrm{ST}}=0.083\right.$ ) and by Carrasco et al. (2012) in Japanese plum cultivars $\left(\mathrm{G}_{\mathrm{ST}}=0.055\right)$. Furthermore, the high variability and recombination is favored by the partial self-incompatibility that exists in the plum genotypes and in particular by the ability of $P$. domestica to form hybrids with other hexaploid species of Prunus as mentioned by Ortiz et al. (1997).

The hierarchical and Bayesian model-based clustering showed that some cultivars under different names are grouped together (HAM1, DLH and TAB) and (Lbyad1 and Lbayda). This result suggests that these cultivars could be synonymous. Indeed, the plum cultivar are denominated by farmer based on their fruit characteristic (skin color, size, origin, flavor) leading often to problem of mislabeling. Similar results were reported in our previous study using morphological parameters.

\section{Materials and methods}

\section{Plant material}

A total of 23 plum cultivars collected from 4 regions in Morocco (group MAR, group BM, group MEK and group TAO) were analyzed in this study (Fig. 3, Table 3). Among these cultivars, 7 are introduced varieties and 16 locally cultivated and denominated by farmers based on their fruit characteristic. The local accessions and the introduced variety Stanley belong to $P$. domestica and the other introduced varieties belong to $P$. salicina. Young leaves collected from all cultivars were kept at $-80^{\circ} \mathrm{C}$ until DNA extraction.

\section{DNA extraction}

DNA was extracted from young leaves using the Isolate II plant DNA kit (Bioline) following the manufacturer's instructions. DNA quality was examined by electrophoresis on $1 \%$ agarose gels and DNA quantity was estimated using the spectrophotometer method.

\section{DNA amplification}

14 ISSR primers previously displayed reliable and polymorphic banding patterns were used in this study (Liu et al., 2007, Athanasiadis et al., 2013). The PCR amplifications were performed in a volume of $12.5 \mu \mathrm{l}$, containing $12 \mathrm{ng}$ of template DNA, $2.5 \mathrm{mM} \mathrm{MgCl}_{2}, 0.8 \mathrm{mM}$ dNTPs, $0.8 \mu \mathrm{M}$ of each primer, $1 \mathrm{X}$ buffer and $0.75 \mathrm{U}$ of Taq DNA polymerase (promega, Madison, WI. USA). All PCR reactions were conducted in a DNA thermocycler (Multigene gradient, Labnet, NJ. USA) through 30 cycles, each consisting of $94^{\circ} \mathrm{C}$ for denaturation step (45 s), $45 \mathrm{~s}$ at the corresponding annealing temperature $\left({ }^{\circ} \mathrm{C}\right)$, and a $72^{\circ} \mathrm{C}$ extension step $(2$ min), using the fastest available transitions between each temperature. Gradient PCR was used to adjust the annealing temperature of each primer. The last cycle was followed by a final extension for $7 \mathrm{~min}$ at $72^{\circ} \mathrm{C}$. PCR products were separated by electrophoresis on $1.7 \%$ agarose with Ethidium Bromide in a TAE buffer and visualized by means of a Gel Doc system (Enduro ${ }^{T M}$ GDS, Labnet). The sizes of amplification products were estimated using DNA marker (1 $\mathrm{Kb}$, Invitrogen)

\section{Data analyses}

ISSR marker is considered to be a dominant marker and amplified alleles for all the samples were scored in a binary data matrix by scoring them as present (1) or absent (0). For each ISSR marker, total amplified bands, number of polymorphic bands, and percentage of polymorphic bands were recorded. The ability of the most informative to differentiate populations was assessed using various parameters: polymorphism information content (PIC) according to De Riek et al. (2001), resolving power (Rp) as described by Prevost et Wilkinson (1999), effective multiplex ratio (EMR) and marker index (MI) according to Powell et al. (1996). The POPGENE 1.32 software was used to determine the following parameters: number of alleles observed $(\mathrm{Na})$, effective number of alleles $(\mathrm{Ne})$, total gene diversity $(\mathrm{Ht})$, gene diversity within groups (Hs), Nei's coefficient of genetic differentiation $\left(\mathrm{G}_{\mathrm{ST}}\right)$ and the Shannon information index (I).

A cluster analysis was conducted using the distance method UPGMA (Unweighted Pair-Group Method with Arithmetic Mean) in the program NTSYS PC version 2.02 computer package program to generate a dendrogram showing relationships among cultivars.

To infer population structure of studied species, the modelbased clustering approach was used by the STRUCTURE v.2.3.4 software program. The STRUCTURE algorithm was run using putative population origin for each individual as prior information, a model with admixture and correlated allele frequencies. Each run involved a burning period length of 50000 and a number of MCMC (Markov Chain Monte Carlo) reps after burnin of 1000 iterations for a number of clusters (K) ranging from 1 to 5 with 20 iterations per K. To identify the number of $K$ clusters explaining the observed genetic structure, we used the STRUCTURE Harvester website (Earl and von Holdt, 2012), which implements the Evanno method (Evanno et al., 2005). 


\section{Conclusion}

The result of this study indicates that, in Morocco, the level of polymorphism in plum is appreciably higher. ISSRs are also very promising genetic markers for cultivars characterization. On the other hand, the analysis of genetic diversity revealed that the clustering of plum cultivars was independent of their geographical origin and their denomination and that the cultivars characterization is the face serious problems regarding synonymy and homonymy. These results should be exploited to resolve mislabeling problem of some cultivars which could be useful to identify the exact number of plum cultivars in Morocco in order to establish a national core collection. It is imperative to increase the number of cultivars and the number of primers tested to access genetic diversity and elaborates a future improvement program.

\section{Acknowledgements}

This work was supported by the Moroccan Ministry of National Education, Vocational Training, Higher Education and Scientific Research through project's University of Sultan Moulay Sliman, Beni Mellal, Morocco.

\section{References}

Ait bella Y, Bouda S, Haddioui A (2018) Phenotypic Diversity Analysis of Plum (Prunus domestica L.) Cultivars. Phytomorphology. 68 (3\&4): 93-101.

Ali SH, Snare DY, Jubrael JM (2015) Analysis of Plum (Prunus domestica L.) Genotypes of Duhok City Using AFLP Markers. International Journal of Bioinformatics and Biomedical Engineering. 1: 64-69.

Aradhya MK, Weeks C, Simon CJ (2004) Molecular characterization of variability and relationships among seven cultivated and selected wild species of Prunus $L$. using amplified fragment length polymorphism. Sci HorticAmsterdam. 103: 131-144.

Athanasiadis I, Nikoloudakis N, Hagidimitriou M (2013) Genetic relatedness among cultivars of the Greek plum Germplasm. Not Bot Horti Agrobo. 41: 49-498.

Baraket G, Abdallah D, Ben Mustapha S, Ben Tamarzizt H, Salhi-Hannachi A (2019) Combination of Simple Sequence Repeat, S -Locus Polymorphism and Phenotypic Data for Identiflcation of Tunisian Plum Species (Prunus spp.). Biochem Genet. 57: 673-694.

Ben Tamarzizt H, Baraket G, Ben Mustapha S, Marrakchi M, Trifi M, Salhi-Hannachi A (2009) Genetic relatedness among Tunisian plum cultivars by random amplified polymorphic DNA analysis and evaluation of phenotypic characters. Sci Hortic-Amsterdam. 121: 440-446.

Ben Mustapha S, Ben Tamarzizt H, Baraket G, Abdallah D, Salhi Hannachi H (2015) Genetic diversity and differentiation in Prunus species (Rosaceae) using chloroplast and mitochondrial DNA CAPS markers. Genet Mol Res. 14 (2): 4177-4188.

Bhutani VP, Joshi VK (1995) Plum. In: Salunkhe, DK and Kadam SS (ed) Handbook of fruit science and technology: production, composition, storage, and processing. Marcel Dekker, New York. pp. 203-241.

Bouhadida M, Martín JP, Eremin G, Pinochet J, Moreno MÁ, Gogorcena Y (2007) Chloroplast DNA diversity in Prunus and its implication on genetic relationships. J Am Soc Hortic Sci. 132: 670-679.

Cao G, Sofic E, Prior RL (1997) Antioxidant and prooxidant behavior of flavonoids: structure-activity relationships. Free Radical Bio Med. 22(5):749-760.

Carrasco B, Díaz C, Moya M, Gebauer M, García-González R (2012) Genetic characterization of Japanese plum cultivars (Prunus salicina) using SSR and ISSR molecular markers. Cienc Investig Agrar. 39: 533-543.

Das B, Ahmed N, Singh P (2011) Prunus diversity early and present development: a review. Int J Biodivers Conserv. 2011, Vol.3, 721-734.

De Riek J, Calsyn E, Everaert I, Van Bockstaele E, De Loose M (2001).AFLP-based alternatives for the assessment of distinctness, uniformity and stability of sugar beet varieties. Theor Appl Genet. 103: 1254-1265.

Earl DA, von Holdt BM (2012) STRUCTURE HARVESTER: a website and program for visualizing STRUCTURE output and implementing the Evanno method. Conserv Genet Resour. 4: 359-361.

Evanno G, Regnaut S and Goudet J (2005) Detecting the number of clusters of individuals using the software STRUCTURE: a simulation study. Mol Ecol. 14: 2611-2620.

Fábregas R (1995) Plum culture, climate and terrain. Multiplication plantation. Graft-poda. Editorial Synthesis SA. The Fronts of Tarrasca. Diseases and enemies, Barcelona, pp. 92.

FAOSTAT (2018) Food and Agriculture Organization of the United Nations. FAO Statistics Division. http://faostat.fao.org/beta/en/\#data/QC.

Hamrick JL, Godt MJW, Sherman-Broyles SL (1992) Factors influencing levels of genetic diversity in woody plant species. New Forest. 6: 95-125.

Horvath A, Balsemin E, Barbot J.-C, Christmann H, Manzano G, Reynet P, Laigret F, Mariette S (2011) Phenotypic variability and genetic structure in plum (Prunus domestica L.), cherry plum ( $P$. cerasifera Ehrh.) and sloe ( $P$. spinosa L.). Sci Hortic-Amsterdam. 129: 283-293.

Hummer, K.E. and Janick, J (2009) Rosaceae: Taxonomy, Economic Importance, Genomics. In: Kevin M F, Susan E G (eds) Genetics and genomics of Rosaceae. Springer, New York, 2009, pp. 1-19.

Ilgin M, Kafkas S, Ercisli S (2009) Molecular characterization of plum cultivars by AFLP markers. Biotechnol Biotech Eq. 23:1189-1193.

Kumar D, Srivastava KK, Singh S R (2018) Morphological and horticultural diversity of plum varieties evaluated under Kashmir conditions. Tropical Plant Research. 5(1): 77-82.

Laabassi ML, Laroussi BF (2010) Bulletin trimestriel d'information du centre régional de la recherche agronomique de Tanger. Maroc.

Liu W, Liu D, Zhang A, Feng C, Yang J, Yoon J, Li S (2007) Genetic diversity and phylogenetic relationships among plum germplasm resources in China assessed with intersimple sequence repeat markers. J Am Soc Hortic Sci. 132(5): 619-628.

Mahhou A, Raquib A (2006) Régulation de la production du prunier japonais Prunus salicina Lind L. à l'aide du cyanamide d'hydrogène "Dormex" dans la région de Rabat au Maroc | INRA. Al Awamia. 3: 118-135.

Manco R, Basile B, Capuozzo C, Scognamiglio P, Forlani M, Rao R, Corrado G (2019) Molecular and Phenotypic Diversity of Traditional European Plum (Prunus domestica 
L.) Germplasm of Southern Italy. Sustainability. 11(15): 4112.

Nisar H, Maqsood A, Sajjad H, and Muhammad AA (2015) Biodiversity in morpho-physiological characteristics of indigenous plum germplasm from Azad Jammu and Kashmir, Pakistan. Zemdirbyste. 102(4): 423-430.

Ortiz A, Renaud R, Calzada I, Ritter E (1997) Analysis of plum cultivars with RAPD markers. J Hortic Sci. 72:1-9.

Oukabli A, Mamouni A (2005) Le prunier. Transfert de technologie en agriculture. Bulletin mensuel d'information et de liaison du PNTTA. Maroc, N 126.

Powell W, Morgante M, Andre C, Hanafey M, Vogel J, Tingey S, Rafalski A (1996) The utility of RFLP, RAPD, AFLP and SSR (microsatellite) markers for germplasm analysis. Mol Breeding. 2: 225-238.
Prevost A, Wilkinson MJ (1999) A new system of comparing PCR primers applied to ISSR fingerprinting of potato cultivars. Theor Appl Genet. 98:107-112.

Ramming DW, Cociu V (1991) Plum (Prunus). Acta Hortic. 290: 235-290.

Stacewicz-Sapuntzakis M, Bowen PE, Hussain EA, DamayantiWood BI, Farnsworth NR (2001) Chemical composition and potential health effects of prunes: a functional food. Crit Rev Food Sci. 41: 251-286.

Walali LDM, Skiredj A (2003) L'abricotier, le prunier, le poirier et le pommier. Transfert de technologie en agriculture, Bulletin mensuel d'information et de liaison du PNTTA. Maroc, N 107.

Wu W, Chen F, Yeh K, Chen J (2018) ISSR Analysis of Genetic Diversity and Structure of Plum Varieties Cultivated in Southern China. Biology. 8(1): 2. 